\title{
XXIV. TÜMEN KOMUTANI YARBAY MAHMUD BEY OLAYI
}

\author{
Yrd. Doç. Dr. Günay ÇAĞLAR
}

1919 ve 1920 yılı içinde İzmit, Adapazarı ve nihayet Bolu ayaklanması adıyla bilinen Hendek, Düzce, ve Bolu'da başlayarak Gerede'ye ulaşan, kısa bir süre sonra Nallıhan ve Beypazarı'na da geçerek, buradan Ankara'ya doğru yaỳılma istidadı gösteren ve üç aydan fazla süren ayaklarmalar, İstanbul Hükümeti ile işbirliği yapan İngilizler' in memleket içinde çıkardıkları ayaklanmaların hedefi dolayısıyla en tehlikeli ve önemlileriridendir. Bu ayaklanma dalgalaıının Ankara'da Sarı Kışla duvarlarına kadar çarptığını Erzurum ve Sivas'da oluşan, sonra Ankara'ya taşınan Heyet-i Temsiliye'nin oturduğu karargaha ulaşan telgraf ve telefon tellerini kesmeğe kadar vardığını gözönüne almak, durumun önemini kavramak için yeterlidir.

Anadolu ve Rumeli Müdâfaai Hukuk Cemiyeti Temsil Heyeti Reisi Mustafa Kemal Paşa, Ankara'yı tehdit eden Düzce Ayaklanması'nı Bolu-Mudurnu hattında durdurmak ve yok etmek için bazı askerî tedbirler aldırdi $1^{1}$.

Bolu'da bulunan sayıları pek fazla olmayan bölge jandarma birliklerinin, Düzceliler'in Bolu'ya girmelerine mani olmak üzere Bolu Dağı Derbendi'nde mevzilenmesi, Geyve'de XXIV. Tümen ile Bolu' nun kuzeydoğusundaki 32. Kafkas Piyade Alayı'nın Devrek üzerinden harekete geçmesi emredildi².

Afyon civarında bulunan Karakeçili Millî Müfrezesi Komutanı Yarbay Arif Bey'e de Bolu'ya yürüme emri verilmiști³.

1 Türk İstiklâl Harbi VI. Cilt, İstiklal Harbinde Ayaklanmalar (1919-1921), Gnkur, Harp Tarihi Bşk. lığı Resmi Yayınları, Ankara 1974 s. 92-93.

2 TBMM Gizli Celse Zabitları I, s. 7-8.

3 Harp Tarihi Belgeleri Dergisi, Sayı 72 (Mart 1975) Belge. 1558, s. 43 . 
Mustafa Kemal Paşa Düzce Bolu harekâtınin başında birtakım askerî tedbirler aldığı gibi adeti olduğu üzere, bölgeye Trabzon Mebusu Binbaşı Hüsrev Bey başkanlığında bir de Heyet-i Nasîha göndermişti ${ }^{4}$. Bolu'ya gönderilen Heyet-i Nasiha'nın görevi; Ankara lehinde propaganda ve millî teşkilat vücuda getirmek, 32. Kafkas Alayı ile buluşarak, birlikte Bolu'ya gitmek, burada Yarbay Mahmud Bey ile teşrîk-i mesâi etmekti .

18 Nisan 1920 akşamı Mustafa Kemal Paşa, Geyve'de XXIV. Tümen Komutanı Yarbay Mahmud Bey'e; “Düzce ayaklanmasını bastırmak üzere, emrindeki kuvvetlerle vakit kaybetmeden Düzce'ye hareket etmesi"6 emrini verdi.

Yarbay Mahmud Bey 143. Alaydan iki tabur, bir dağ bataryası ve süvari takimından kurulu bir kuvvetle 19 Nisan $1920^{7}$ günü - sabah erken saatlerde Geyve'den hareket ederek ${ }^{8}$, güneş batmak üzere iken Adapazarı'na girdi. Mahmut Bey, burada soğuk bir hava ile karşılaşmıştır. Düzce'de gelişen hadiseler dolayısıyla, Kuvây-1 Milliyeciler'e taraftar görünmeyen Adapazarlılar, askeri endişe ile seyrettiler. Bu arada dükkanlar da kapatılmaya başlanmıştı. Mahmud Bey, karargahını emniyet altına aldırdıktan, İstanbul ile olan bağlantı ve haberleşmeyi kestikten sonra, geceyi Adapazarı'nda geçirdi. Ertesi gün geçeceği yollardaki ahaliye dağıttırmak üzere; "Padişah ve Halife, İngilizler' in eline esir düşmüştür. Padişahımızı kurtarmak için ölünceye kadar çalıșacağız. İstanbul Hükümeti İngilizler'in elinde bir oyuncaktan başka bir şey değildir. Padișah ve milleti kurtarmak maksadiyle harekete geçen Kuvây-1 Milliye'ye yardım ediniz" şeklinde, halkı millî harekete yardıma çağıran el ilânları hazırlattı" "9.

4. Günay Çağlar, Hüsrev Bey Heyet-i Nasîhası (Nisan-Haziran 1920) (Basılmamış Yüksek Lisans Tezi) Erzurum 1985.

5 Türk Inkılâp Tarihi Enstitüsü Arşivi, No: 21 / 3001-3005, s. 2-3.

6 Harp Tarihi Belgeleri Dergisi, Sayı: 74 (Mart 1976) Belge. 1597, Ali Fuat Cebesoy, Millî Mücadele Hatıraları, İstanbul 1953, s. 360. Ali Fuat Cebesoy, telgrafin tebligat tarihi olarak 19 Nisan akşaminı vermiştir. Bkz. Cebesoy, Milli Mücadele Hatıraları, s. 360.

7 Bu tarih için Ali Fuat Cebesoy 20 Nisan sabahını vermiştir. Bkz. Cebesoy, Milli Mücadele Hatıralan, s. 360 .

8 Türk İstiklâl Harbi VI. cilt, İstiklâl Harbinde Ayaklanmalar (1919-1921), s. 94.

9 Cebesoy, Milli Mücadele Hatıraları, s. 360. 
Bir gün sonra Hendeke hareket edildi. Her köy geçildikçe Mahmud Bey, askerleriyle buralara beyanname dağıttırd 10 .

XXIV. Tümen 21 Nisan 1920 günü akşam üzeri Hendek'e vardı. Burada da, Adapazarı'nda olduğu gibi, garip bir hava hüküm sürmekteydi. Dükkanlar kapatılmış, halk evlerine ve köylerine çekilmişti. Yarbay Mahmud Bey, tellâllar vasitasıyla, halkın hükümet meydanında toplanmasını ve kendileriyle görüşmek istediğini ilân ettirmişti. $\mathrm{Bu}$ davete yalnız meraklı çocuklar gelmişti. Yarbay Mahmud Bey, bölge halkının tek taraflı propagandayla nasıl kandırıldığına şahit oluyordu11. Bu şartlar altında, Tümen'in güvenliği için sıkı tedbirler alınarak, gece Hendek'te geçirildi. Gece olaysız geçti. Ancak, Hendek köylerinde olağanüstü şeyler cereyan etmekteydi. Düzce ayaklanmasına taraftar olan bir kısım Hendekliler ve Damad Ferid Paşa taraftarları, o gece sabaha kadar süren yoğun bir faaliyet içine girdiler. Tümen Komutanı'nın Hendek'e gelişini; “Bolşevikler Hendek'i bastı. Kadın ve kızlarımızı hamamlara, doldurdular. Müslümanlık ve namusumuz tehlikededir. Allahını seven Hendek'e koşsun!" gibi doğru olmayan yanıltıcı haberleri yaydılar. Böylece halkı asker aleyhine kışkırtmış oldular ${ }^{12}$.

22 Nisan sabahı Adapazarı-Hendek arasındaki Yağbasan köyünden hareket eden müfreze, birinci tabur önde, batarya ortada, ikinci tabur arkada olmak üzere, Nüfren boğazı içinden Düzce'ye doğru yürüyüșe başladı1 ${ }^{13}$. Tümen karargâhı arkadan gelecekti. Bu sırada, arazide kendini belli etmeyen kalabalık bir âsî grubu, Uludere'nin hemen doğusundaki Hüseyin şeyh'e doğru uzanan Sarıbayırlar'da gizlenerek mevzilenmişti14. Düzce'ye doğru ilerlemekte olan Tümen'in

10 Cebesoy, Milli Mücadele Hatıraları, s. 360 .

11 Cebesoy, Milli Mücadele Hatiraları, s. 360.

12 Cebesoy, Milli Mücadele Hatıralar, s. 361;

Halide Edip Adıvar da bu konuda şunları yazmaktadır:

"Aynı zamanda Albay Mahmut Bey de Hendekten Bolu üzerine yürüyordu. Insanca hareketi sayesinde, halkın sevgisini kazanmıştı. Hilâfetçiler, bunu görünce, Mahmut Bey'in adamlarını kendi taraflarına çekmek için her türlü girişimde bulunmuşlardı. Onlar Hendekten geçerken, minarelerden "Kardeş kanına nasıl gireceksiniz ?" diye sesler duyulmaya başlamıştı." Bkz. Halide Edip Adıvar, Türkün Ateşle İmtihanı, İstanbul 1983, s. 122.

13 Cebesoy, Milli Mücadele Hatıraları, s. 360.

14 Harp Tarihi Belgeleri Dergisi, sayı 74 (Mart 1976), Belge, 1600. 
öncüleri, Hendek çıkışından yarım saat sonra asilerin ateşiyle karşılaştılar. Kaymakam Mahmut Bey, bu durumdan haberdar olur olmaz karargahı ile birlikte yürüyüşe geçti. Bu sırada, bir ihtiyar Mahmud Bey'in önüne çıkarak onunla bir șeyler konuşmak istediğini söyledi.

Yarbay Mahmud Bey ihtiyarın konuşmalarını din'edikten sonra, atlılardan birini indirerek, bu ihtiyarı ata bindirdi ve beraberce kasabadan çıktılar. Kasabanın hemen dışında ve doğusunda Uluçay üzerindeki köprüye vardıklarında, topçuların oldukları yerde sıkışıp kaldıklarını ve asilerin birkaç hayvanı vurmuş olduğunu gördü. Piyade bölümleri mevzi almıș, asilere ateș etmekteydi. Tümen Komutanı köprü başında süvari takımını ve karargahını bırakarak, yanına yaverini, mülhakını ve ihtiyar adamı alarak mevzi almış I. tabura doğru koşar adımlarla ilerledi. Ateş altında üçyüz metre kadar yol aldıktan sonra, ihtiyarı asilere doğru gönderdi. Bu esnada taraftarların ateşleri devam etmekteydi. Mahmud Bey'in amacı kardeş kanı dökülmeden anlaşma yoluyla, duruma hakim olabilmekti. Bu yüzden, ihtiyarı Düzce şosesi yönünde asilere doğru gönderdi. Bu esnada ateșkes emri de verdi. $\mathrm{Bu}$ emir üzerine I. tabur ateşini hemen kesti. II. tabur da bu esnada yeni mevzi almış ve henüz ateşe başlamıştı. Tümen komutanı, bu defa II. tabura ateș kestirmek için giderken, I. taburdan Mülazım Muhsin'in komutasında bulunan I. bölüğün silâh çatarak asilerle kucaklaştıklarını, erlerin gafletinden yararlanan asilerin ise, bölüğün silahlarını toplamaya başladiklarını gördü. Bu durum üzerine Tümen Kurmay Başkanı ateşe devam edilmesini teklif etti ise de, Mahmud Bey, biraz dayanıklılık ve sabır gösterilmesini soğukkanlılıkla çarpışmanın önünün alınabileceğini söyledi. Bu arada sağdaki II. tabur da ateş kesmişti. Ateş kesilir kesilmez, bu taburun içine asiler girivermişlerdi. Bu esnada, onbeş-yirmi adım kadar bir uzaklıktan bir asi de Mahmud Bey'e doğru fırlamış ve ona hitaben, "teslim ol, teslim ol" diye bağırmışıtı. Tümen Komutanı geçte olsa aldanmış olduğunu anladı ve yanındaki yaverin filintasını alarak asilerin üzerine ateş etti. Fakat, heyecanlı olduğu için, isabet ettiremedi. Hazırlıklı olan ásilerden beş kişi, tüfeklerini aynı anda ateşlediler. Bir kurşun sol bileğinden, bir kurşun da karnından, Mahmud Bey'i yere yıkmıştı. Yanındaki subaylar derhal müdahalede de bulundular. Fakat, ne yazık ki, Mahmud Bey vefat etmiş, katilleri de kaçmışlardı. Müfreze ağırlıklarını orta yerde birakmış ve yağmaya uğramıștı. Diğer taraftan, Kurmay Yakub Sami ve Levazım Başkanı Rıfkı Beyler de Máhmud Bey ile beraber şehid düș- 
müşlerdi15. İki saat içerisinde, XXIV. Tümen birdenbire dağılmış ve Ali Fuad Paşa'nın işaret ettiği gibi, söz ayağa düşmüştü. Subaylar ele geçirilmiş, erlerin silahları alınarak, tesirsiz hale getirilmişlerdi16.

Kısa bir süre sonra XXIV. Tümen'in esir edilen bazı sụbay ve askerleri Düzce'ye götürüldüler. Burada, subaylar askerlerden ayrılarak, Hürriyet ve İtilâf Fırkası binasında göz altına alındılar ${ }^{17}$.

Yarbay Mahmud Bey'in ölümü ve kuvvetlerinin dağıldığı haberi bir yıldırım hızı ile ayaklanma sahalarında yayıldı. Bu durum asilerin prestijini artırdı. Gerede'de asi liderlerinden Kör Ali ve Divitli Eşref Hoca bunu halka müjdelerken, Bolu hilafetçileri de ister istemez aynı sevince katılmışlardı. Mudurnu'ya da bir telgraf gönderilmiş ve telgrafçı Hamdi Bey tarafından hadise ahaliye duyurulmuştu. Bu haber Mudurnu hilafetçilerini sevince boğarken, Kuvây-1 Milliyetcileri de derin acılara düşürmüştü ${ }^{18}$.

Hendekliler, Adapazarı'nı almak ve oradaki taraftarlarıyla birleşmek üzere, yürümeğe karar verdikleri bir sırada 23 Nisan 1920 günü, Adapazarı ileri gelenlerinden Said Bey başkanlığında bir heyet-i nasiha Hendek'e doğru yola çıtı. Budaklar köyünde asilere rastlanıldı. Asiler onları iyi karșılamadılar. Heyetten Said ve Kâzım Beyler'i öldürdüler. Bu durum Garp Cephesi Komutani Ali Fuad Paşa'nın acil tedbirler almasını gerektirdi ${ }^{19}$.

Bolu bölgesinde Milli Hükümet aleyhindeki ayaklanma, $22 \mathrm{Ni}-$ san 1920'de ayaklananların istediği hedeflere ulașmıștı. Ayaklanma Düzce-Bolu ve Gerede çizgisinde ağırlık kazanmıştı. Düzce'den doğuya doğru yayilan yangin 23 Nisan 1920 'de Gerede'yi de etkisi altına almaya başlamıştı ${ }^{20}$.

15 Cebesoy, Milli Mücadele Hatıraları, s. 361-362;

Türk İstiklâl Harbi VI. cilt, İstiklâl Harbinde Ayaklanmalar (19191921), s. 95.

16. Cebesoy, Milli Mücadele Hatiraları, s. 362.

17 Rahmi Apak, İstiklâl Savaşında Garp Cephesi Nasıl Kuruldu, İstanbul 1942, s. 115; Yunus Nadi, Kurtuluş Savaşı Anılan, İstanbul 1978, s. 300-301.

18 Selim Saribay, İstiklal Savaşında Mudurnu -Bolu-Düzce, Sunan: A. Utkun Boyacigiller, Aydın 1943, s. 45-46.

19 Türk İstiklâl Harbi VI. eilt, İstiklâl Harbinde Ayaklanmalar (1919-1921), s. 95-96.

20 Türk İstiklâl Harbi VI. cilt, İstiklâl Harbinde Ayaklanmalar (1919-1921), s. 99. 
Herşeyden habersiz, Gerede'ye doğru ilerlemekte olan Binbaşı Hüsrev Bey Heyet-i Nasîhas, hiç umulmadık bir anda Kasaba civarında âsilerin tuzağına düşürülmüş, Hüsrev Bey ve arkadașları önce Gerede'de ve sonra da Düzce'de gözaltına alınmışlardı. Bu da onlar da büyük bir üzüntüye yol açmışt. Ama, Heyet-i Nasîha üyelerini asıl ümitsizliğe düşüren hadise, bütün ümitlerini bağlamış oldukları Yarbay Mahmud Bey'in ve XXIV. Tümen'in başına gelenler olmuştur'21.

Hüsrev Bey başkanlığındaki Heyet-i Nasîha'nın üyeleringden Bolu Mebusu Dr. Fuad Bey küçük hatıratında bu konuda "22 Nisan' da dellâl, Kaymakam Mahmud Bey'in maiyetiyle beraber esir edildiği, dört top, dört mitralyöz alındığını bağırmıştı. Bunun blöf olduğunu hükmetmişti. Bütün ümidimiz Mahmud Bey'de idi. Mahmut Bey Düzce ile İstanbul'un muvasalasını (ulaşımını) kestikten sonra mesele kolaylaşacaktı. $\mathrm{Bu}$ haber bize pek ziyâde tesir etti. Maalesef itimat ettiğimiz nöbetçi de bunu teyid etmişti." demektedir ${ }^{22}$.

Binbaşı Hüsrev Bey ile arkadaşları Nisan ayının son günlerinde, Çerkes Nuri Bey'in gözetiminde Gerede'den Düzce'ye götürülürlerken, Bolu geçildikten sonra, yollarda ellerinde beyaz bayraklar taşıyarak evlerine dönmekte olan beşer-onar kişilik küçük askeri gruplara rastlamışlardır. Bunlar, XXIV. Tümenin felâkete uğramasından sonra, asiler tarafından Düzcede terhis edilen Kaymakam Mahmud Bey'in askerleriydiler ${ }^{23}$.

Heyet-i Nasîha üyeleri, Düzce'de Hürriyet ve İtilaf Fırkası binasında kalmışlardır. Burada kendileri gibi göz altında tutulan subaylarla karşılaşmışlardır. Bunlar Düzce ayaklanması sırasında tutuklananlar, XXIV. Tümen'in subayları ve 32. Kafkas Alayı'nın subayları idiler ${ }^{24}$. Şehit Yarbay Mahmut Bey'in Tümeni'ne mensup subaylar, Hüsrev Bey ve arkadaşlarının Gerede hapishanesinde duymuş olduklarını, geniş ve tatmin edici bir şekilde anlatmışlardır ${ }^{25}$.

XXIV. Tümen'in Komutanı Yarbay Mahmud Bey'in komutanlarından ve yakın arkadaşlarından XX. Kolordu Komutanı Ali Fuad

21 Türk Inkılâp Tarihi Enstitüsü Arşivi, No: 21/3001-3005, s. 8.

22 Yunus Nadi, Kurtuluş Savaşı Anıları, s. 300.

23 Türk İnkılâp Tarihi Enstitüsü Arşivi, No: 21/3001-3005, s. 8.

24 Türk Inkılâp Tarihi Enstitüsü Arşivi, No: 21/3001-3005, s. 8-9; Yunus Nadi, Kurtuluş Savaşı Anıları, s. 300-301.

25 Türk İnkılâp Tarihi Enstitüsü Arşivi, No: 21/3001-3005, s. 9. 
Paşa da Fırka'nın fecî sonunu, Bursa'da BMM'nin açılışı için tören hazırlıkları yaparken, Bilecik Mutasarrıflı̆ı aracılığıyla öğrenmişti. Ali Fuad Paşa, Milli Mücadele Hatıraları'nda bu konudaki hislerini şu şekilde dile getirmiştir ${ }^{26}$.

"İçimiz kan ağlıyordu. Millî harekâtın başından beri Erkân-1 Milliye ve kumandanları arasında yüksek hamiyet ve fedâkarlığı ile halk ve asker arasında iktidarıyla cesâretiyle tanınmış olan Fırka Kumandanı Mahmud Bey șehid olmuștu."

Düzce-Bolu ayaklanmasının ortaya çıkışında ve yayılmasında birçok unsur etkili olmuștur. Düzce ve havalisínde işlenen ve fena sonuçlar doğuran propagandalardan biri de, Damad Ferit Paşa Hükümetleri'nin yaymaktan çekinmediği Bolşeviklikti. Damad Ferid Paşa, Süleyman Şefik, v.s. devlet adamları Anadolu'ya birtakım Bolşeviklerin girdiğini, Kuvây-1 Milliye harekâtının Bolşeviklikten başka bir şey olmadığını resmen ilân etmislerdi27. Bolşeviklik propagandası, BMM Hükümeti ile SSCB arasında resmi ilișkiler bașlamadan çok önceleri, Düzce havalisinde etkili olmaya başlamıştı. Kaymakam Mahmut Bey hadisesinin meydana gelmesinde, en önemli etken Bolşeviklik propagandas! olmuştur ${ }^{28}$. Bolu faciasından sonra, bilindiği gibi, Mutasarrıf Osman Nuri Bey Bolşevikliği silah olarak kullandığı bir beyanname yay:nlamıştı2 29 .

BMM'nir açılışından bir gün önce meydana gelen XXIV. Tümen olayı, az sonra Ankara'da duyulmuștu. Haber Ankara'da özellikle, Yarbay Mahmud Bey'i yakından tanıyanlar arasında büyük bir üzüntüye sebebiyet vermişti. ${ }^{30}$ BMM'nin 1 Mayis 1336 günkü gizli oturumunda, Mustafa Kema' Paşa'dan sonra söz alan Antalya Mebusu Hamdullah Subhi Bey'in kürsüden; "Mahmud Bey șehid oldu. Mübarek nâşı üzerinde ağlayacağımız gençlerden biridir." 31 diyen sesi Meclisin duvarlarında yar.kılanmıştır.

26 Cebesoy, Milli Mücadele Hatıralan, S. 362.

27 Gazi Mustafa Kemal, Atatürk, Nutuk, Ankara 1927, s. 1029.

28 Cebesoy Milli Mücadele Hatıraları, s. 360.

29 Kâzım Aras, İstiklal Savaşında Kocaeli Bölgesindeki Harekât, 102 Sayılı Askerî Mecmua'nın Tarih Kısmı, 1936, s. 9-11.

30 Adıvar, Türk'ün Ateşle İmtihanı, s. 122.

31 TBMM Gizli Celse Zabitları I, s. 9. 
Evet, Hamdullah Subhi Bey'in de işaret ettiği gibi, millet arkasından uzun süre ağlayacağı vatanperver bir evladını daha kaybetmiști. Türk Milleti ancak bu fedakar vatan evlatları sayesinde Milli Mücadele'den başarılı çıkmıştır. Yarbay Mahmut Bey ve arkadaşları milletimizin ne ilk şehitleridir, ne de son șehitleri olacaktır. Onlar milletin kalbinde ilelebet yaşayacaklardır. 